\title{
Base-free Knoevenagel condensation catalyzed by copper metal surfaces $\dagger$
}

Cite this: Chem. Commun., 2015, 51, 10695

Received 27th March 2015,

Accepted 16th May 2015

DOI: $10.1039 / c 5 c c 02541 a$

www.rsc.org/chemcomm

For the first time Knoevenagel condensation has been catalyzed by elemental copper with unexpected activity and excellent isolated yields. Inexpensive, widely available copper powder was used to catalyze the condensation of cyanoacetate and benzaldehyde under mild conditions. To ensure general applicability, a wide variety of different substrates was successfully reacted.

Copper has been a fascinating element in catalysis for decades. ${ }^{1}$ In the early days of copper catalysis, famous name reactions such as the Ullmann coupling, ${ }^{2}$ the Sandmeyer reaction and the Chan-Evans-Lam coupling have emerged. ${ }^{3}$ Around the millennium, Sharpless and coworkers developed the extremely important "click chemistry", in which the copper catalyzed azide-alkyne Huisgen cycloaddition (CuAAc) plays the most essential role. ${ }^{4}$ However, much more expensive noble metals such as platinum, palladium and gold have received most attention in the field of catalysis, while the inexpensive yet semi-noble copper has been more or less neglected. ${ }^{5}$ Knoevenagel condensation (Scheme 1) is a widely used reaction in research and industry and has been of importance for several pharmaceutical products. ${ }^{6}$ Generally this reaction is catalyzed by organo-bases, such as pyridine or piperidine. But using these homogeneous base catalysts often leads to time consuming work-up procedures. Additionally, undesired side-reactions such as oligomerizations can occur, high temperatures are necessary, and catalyst recovery is difficult. ${ }^{7}$ Thus, numerous accounts on heterogeneous Knoevenagel catalysts, for example modified zeolites, ionic liquids or magnetic base analogues, have been reported. ${ }^{8}$ This leads to cleaner products while complex neutralization procedures can be avoided. ${ }^{4 b}$ Moreover, these catalysts can be recovered and regenerated. Within one of these studies it was shown that carbon-coated

${ }^{a}$ Institute for Chemical and Bioengineering, ETH Zurich, Vladimir-Prelog-Weg 1, 8093 Zurich, Switzerland. E-mail: wendelin.stark@chem.ethz.ch

${ }^{b}$ Laboratory for Multifunctional Materials, Department of Materials, ETH Zurich, Vladimir-Prelog-Weg 5, 8093 Zurich, Switzerland

$\dagger$ Electronic supplementary information (ESI) available: Experimental procedures, supplementary kinetic figures, SEM micrographs, X-ray crystallographic analysis and ${ }^{1} \mathrm{H}$ and ${ }^{13} \mathrm{C}$ NMR spectra. See DOI: 10.1039/c5cc02541a

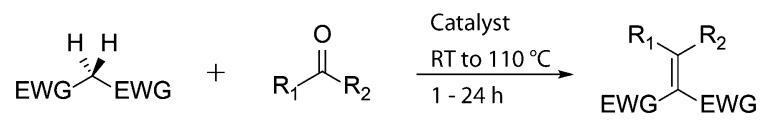

Scheme 1 Knoevenagel condensation of an active methylene compound with an aldehyde or ketone.

cobalt nanoparticles $(\mathrm{C} / \mathrm{Co})^{9}$ showed some activity in the Knoevenagel condensation if compared to the uncatalyzed reaction (entries 1 and 2, Table 1). ${ }^{8 e}$ As a consequence of these results, several other carbon coated nanoparticles were tested; amongst which carbon-coated copper nanoparticles $(\mathrm{C} / \mathrm{Cu})^{10}$ showed the highest activity. As reference, we compared the nanoparticles with pure metal powders. These experiments afforded the insight that commercially available, dendritic copper powder $\mathrm{Cu}(\mathrm{D})$ catalyses the Knoevenagel condensation of benzaldehyde $\mathbf{1}$

Table 1 Activity of different catalysts for the Knoevenagel reaction of benzaldehyde and ethyl cyanoacetate ${ }^{a}$

\begin{tabular}{lllc}
\hline & & & \\
\hline
\end{tabular}

${ }^{a}$ Reaction conditions: catalyst $(4 \mathrm{mg})$, benzaldehyde $(0.12 \mathrm{mmol})$ and ethyl cyanoacetate $(0.1 \mathrm{mmol})$ in $1 \mathrm{~mL}$ of EtOH for $2 \mathrm{~h} .{ }^{b}$ Only the $E$-isomer was detected, yield determined via HPLC-UV (MS) using commercial product 3 as the reference standard. 
Table 2 Optimization of the reaction conditions ${ }^{a}$

\begin{tabular}{llcccc}
\hline Entry & Solvent & Loading $(\mathrm{mg})$ & $t(\mathrm{~h})$ & $\mathrm{Cu}^{b}(\mathrm{ppm})$ & Yield $^{c}(\%)$ \\
\hline 1 & EtOH & 0.4 & 2 & 3 & 6 \\
2 & EtOH & 2 & 2 & 38 & 14 \\
3 & EtOH & 4 & 2 & 44 & 32 \\
4 & EtOH & 10 & 2 & 216 & $96(95)^{d}$ \\
5 & EtOH & 40 & 2 & 114 & $99(85)^{d}$ \\
6 & EtOH & 4 & 6 & 44 & $99(95)^{d}$ \\
7 & Acetone & 4 & 20 & 18 & 1 \\
8 & Cyclohexane & 4 & 20 & 32 & 3 \\
9 & Toluene & 4 & 20 & 30 & 3 \\
10 & DMF & 4 & 6 & 17 & $99(98)^{d}$ \\
11 & DMSO & 4 & 2 & 241 & 99 \\
12 & MeCN & 4 & 2 & 230 & $99(98)^{d}$
\end{tabular}

${ }^{a}$ Reaction conditions: copper $(4 \mathrm{mg})$, benzaldehyde $(0.12 \mathrm{mmol})$ and ethylcyanoacetate $(0.1 \mathrm{mmol}) .{ }^{b} \mathrm{Cu}$ leaching measured by ICP-OES. ${ }^{c}$ Determined via HPLC-UV using commercial product 3 as the reference standard. ${ }^{d}$ Isolated yield.

and cyanoacetate 2 in ethanol to 3 (entry 8, Table 1) with enhanced yields. Compared to other heterogeneous catalysts for the Knoevenagel condensation, the unmodified, commercially available copper does not need any special treatment, synthesis procedure or sophisticated storage and is the base stock in many laboratories. Notable is the fact that silver, gold, $\mathrm{ZnCl}_{2}$ and brass showed only low activities compared to elemental copper (entries 9-12). To optimize the reaction conditions the catalyst loading was varied, and as expected higher loading resulted in higher yields (up to 99\%; entries 1-5, Table 2). It should be noted that an equivalent amount of copper compared to the reagents is not imperative to result in full conversion (entry 6). Optimization tests with different solvents clearly favoured aprotic, polar solvents over non-polar solvents (entries 7-12). These results are in line with the general literature on Knoevenagel condensation, namely with the first step in the reaction mechanism which is the generation of an anion at the $\alpha$-position of the carbonyl group followed by enolate formation. ${ }^{7}$ After optimizing the reaction conditions with the model substrates, a variety of different aldehydes and active methylene compounds were reacted (Table 3). As already summarised by Tietze et al., all condensations using 2 as the substrate exclusively yielded the $E$-isomer. ${ }^{7}$ Other active methylene compounds were tested, such as Meldrum's Acid (entry 6) and analogues (yielding the bis-adduct, entry 5), the very reactive malononitrile (99\% yield in $1 \mathrm{~h}$, entry 8 ) and the less reactive ethylacetoacetate ( $23 \%$ yield after $15 \mathrm{~h}$, entry 9 ). The different reactivities of these compounds are well known and correlate with their ability of stabilizing the corresponding anion. ${ }^{7}$ To gain more detailed insight into the reaction mechanism, further experiments concerning the nature of the copper catalyst have been conducted.

A possible first hypothesis was that copper leaching, i.e. soluble $\mathrm{Cu}$ (I) or $\mathrm{Cu}$ (II) species, could be the reason for catalytic activity. Several Cu(I/II) compounds have been tested (entries 1-5, Table 4) to investigate the activity of copper ions in solution. None of these copper species showed substantial activity, instead of a high measured solvated $\mathrm{Cu}$ amount (entries 2 and 3). Also, there are reports of metal-alkoxide catalysed Knoevenagel condensations, and activity of in situ generated CuOMe may also be
Table 3 Scope of the condensation ${ }^{a}$

Entry Reactant

${ }^{a}$ Reaction conditions: $\mathrm{Cu}(20 \mathrm{mg})$, aldehyde $(0.21 \mathrm{mmol})$ and active methylene $(0.2 \mathrm{mmol})$ in EtOH for $6 \mathrm{~h}$ at $56{ }^{\circ} \mathrm{C}$. ${ }^{b}$ Yield determined via HPLC-UV or GC-FID. ${ }^{c}$ Stirred for $16 \mathrm{~h} .{ }^{d}$ Isolated yield, only the $E$-isomer was detected. ${ }^{e} 6 \mathrm{~h}$ in DMF. ${ }^{f}$ Stirred for $1 \mathrm{~h}$ at RT. ${ }^{g}$ Stirred for $15 \mathrm{~h}$ in DMSO at $70{ }^{\circ} \mathrm{C}, E / Z=65 \%: 35 \%$.

possible. ${ }^{11}$ However, if the solid catalyst is filtered (Fig. 1), conversion stops immediately. This leads to the conclusions that either there is a very unstable homogeneous reactive species formed on the surface of $\mathrm{Cu}$ or leaching is not the reason for catalytic activity. Hence, a second hypothesis can be formulated around $\mathrm{Cu}$ surface based catalysis, where the yield is expected to correlate with the specific surface area (SSA) of the catalyst. $\mathrm{Cu}(\mathrm{D})$ has dendritic structures between $0.5-1 \mu \mathrm{m}$ (see Fig. S4, ESI $\dagger$ ) and thus a relatively low BET surface area of $0.2 \mathrm{~m}^{2} \mathrm{~g}^{-1}$. While a tenfold larger amount of $\mathrm{Cu}(\mathrm{D})$ resulted in a tenfold 
Table 4 Copper containing reference substances as catalysts for the Knoevenagel condensation ${ }^{a}$

\begin{tabular}{|c|c|c|c|c|c|}
\hline Entry & Catalyst & Time (h) & $\operatorname{SSA}\left(\mathrm{m}^{2} 10^{-4}\right)$ & $\mathrm{Cu}(\mathrm{ppm})$ & Yield $^{b}(\%)$ \\
\hline 1 & $\mathrm{Cu}(\mathrm{II})_{2}(\mathrm{OH})_{2} \mathrm{CO}_{3}$ & 2 & - & 6 & 2 \\
\hline 2 & $\mathrm{Cu}(\mathrm{II}) \mathrm{Cl}_{2}$ & 16 & - & 740 & 1 \\
\hline 3 & $\mathrm{Cu}(\mathrm{I}) \mathrm{Cl}$ & 16 & - & 460 & 3 \\
\hline 4 & $\mathrm{Cu}(\mathrm{II}) \mathrm{O}$ & 20 & - & 6 & 4 \\
\hline 5 & $\mathrm{Cu}(\mathrm{I})_{2} \mathrm{O}$ & 20 & - & 12 & 14 \\
\hline 6 & $\mathrm{Cu}(\mathrm{D})$ & 2 & 8 & 44 & 32 \\
\hline $7^{c}$ & $\mathrm{Cu}(\mathrm{D})$ & 2 & 80 & 114 & 99 \\
\hline 8 & $\mathrm{Cu}(\mathrm{Hol})$ & 2 & 84 & 62 & 65 \\
\hline 9 & $\mathrm{Cu}(\mathrm{NPA})$ & 2 & 168 & 176 & 96 \\
\hline 10 & $\mathrm{Cu}(\mathrm{NPB})$ & 2 & 636 & 197 & 99 \\
\hline
\end{tabular}

${ }^{a}$ Reaction conditions: catalyst $(4 \mathrm{mg})$, benzaldehyde $(0.12 \mathrm{mmol})$ and ethyl cyanoacetate $(0.1 \mathrm{mmol})$ in EtOH at $56{ }^{\circ} \mathrm{C} .{ }^{b}$ Yield determined via HPLC-UV (MS) using commercial product 3 as the reference standard. ${ }^{c} 40 \mathrm{mg}$ of $\mathrm{Cu}(\mathrm{D})$ used.

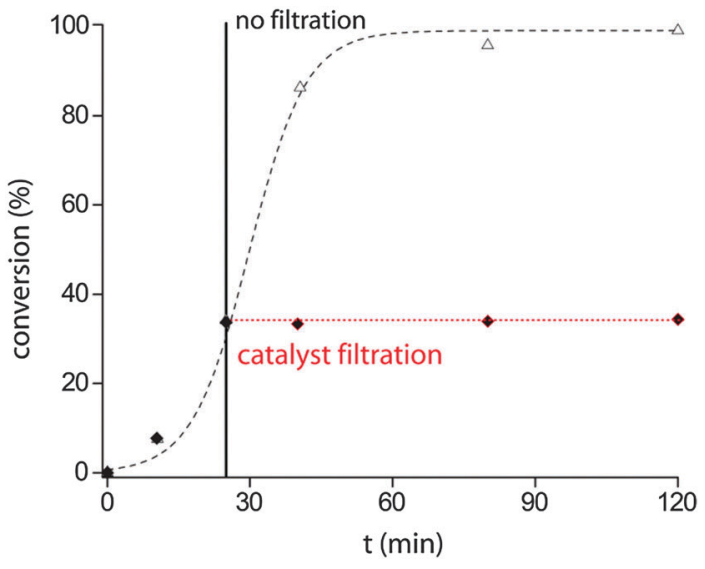

Fig. 1 Knoevenagel condensation of benzaldehyde $(0.12 \mathrm{mmol})$ and ethyl cyanoacetate $(0.1 \mathrm{mmol})$ with copper $\mathrm{Cu}(\mathrm{D})(4 \mathrm{mg})$ at $56^{\circ} \mathrm{C}$ in DMSO: after 20 minutes half of the reaction volume was extracted and filtered and further subjected to the reaction conditions without a solid catalyst (black diamonds).

larger surface area, leaching was only increased by factor 2.5 (entries 6 and 7), yet the yield substantially changed from $32 \%$ to $99 \%$. This is another argument against a mechanism based on solvated $\mathrm{Cu}$ species, since the relatively small amount of additional leached species, for example in the case of Copper hollow-spheres $(\mathrm{Cu}(\mathrm{Hol})$, entry 8 , Table 4$)$, can hardly be responsible for the large increase in yield. Thus, a $\mathrm{Cu}$ surface based mechanism can be assumed. However, the nature of the surface state required for catalytic action is still unknown. Thus, surface activation experiments were done: the copper catalyst was pretreated under different reducing conditions, in order to reduce copper oxide species. This resulted in higher yields, most obviously for toluene, where the pre-treated copper yielded $53 \%$ product after $20 \mathrm{~h}$, while the untreated copper did not catalyze the reaction at all (entries 4 and 5, Table 5). This finding leads to the conclusion that a non-oxidized $\mathrm{Cu}(0)$ surface reacts with the substrates. Kinetic measurements support the surface catalyzed mechanism too, as a zero-order kinetic model fits well in the beginning of the reaction (see Fig. S1 and S2 in the ESI†). An initial TOF of $0.88 \mathrm{~s}^{-1}$ was calculated using optimal
Table 5 Effect of surface activation of $\mathrm{Cu}(0)$ on the reaction rate ${ }^{a}$

\begin{tabular}{lllllll}
\hline & \\
\hline & & & & & \\
\hline
\end{tabular}

${ }^{a}$ Reaction conditions: pre-treated catalyst $(4 \mathrm{mg})$, benzaldehyde $(0.21 \mathrm{mmol})$ and ethyl cyanoacetate $(0.2 \mathrm{mmol})$ at $56{ }^{\circ} \mathrm{C} .{ }^{b}$ Yield determined via HPLC-UV (MS) using commercial product 3 as the reference standard. ${ }^{c}$ In $2 \%$ formic acid.

conditions (Fig. 1, 41\% yield after $30 \mathrm{~min}$ ) and the conservative assumption that every $\mathrm{Cu}(0)$ atom on the surface is an active site. Further mechanistic studies are a subject of ongoing research. Moreover, similar copper(0) species with different BET surface areas (see Table S1 in the ESI $\dagger$ ), such as copper hollow spheres $\mathrm{Cu}(\mathrm{hol}),{ }^{12}$ copper nanoparticles $\mathrm{A} \mathrm{Cu}(\mathrm{NPA})$ and copper nanoparticles B $\mathrm{Cu}(\mathrm{NPA})$ were tested (entries 8-10). A correlation between the surface area and conversion could be confirmed. Also, an experiment was conducted to prove the reusability of the catalyst. The standard setup in DMSO afforded constant high yields after $1 \mathrm{~h}$ for 5 consecutive cycles (Fig. S1, ESI †).

To illustrate the practical synthetic utility of our method, a 100 gram scale experiment was performed (Scheme 1). Benzaldehyde 1 ( $81.2 \mathrm{~mL}, 0.8 \mathrm{~mol}$ ) was reacted with ethyl cyanoacetate $2(84.8 \mathrm{~mL}, 0.8 \mathrm{~mol})$ and $16.00 \pm 0.001 \mathrm{~g}$ of $\mathrm{Cu}(\mathrm{D})$ in EtOH at $56^{\circ} \mathrm{C}$ for $16 \mathrm{~h}$. After filtration through aluminum oxide and recrystallization, 91\% (146 g) pure isolated yield was obtained and almost all of the solid catalyst $(15.94 \pm 0.001 \mathrm{~g})$ could be recovered. This satisfying result highlights the simplicity of both catalyst and work-up and hence is of interest for industrial scale Knoevenagel reactions. It should be noted that this kind of upscale experiment is difficult to perform with soluble base catalysts as large amounts of solvent and neutralization agent have to be used.

In summary, we have developed a simple and mild method for the Knoevenagel condensation using commercially available semi-noble copper. In this catalysis, tedious separation procedures are not necessary and no traces of base remain. Further experiments revealed that a $\mathrm{Cu}(0)$ surface is necessary to catalyze the condensation and, surprisingly, other noble metals such as gold and silver were not active. Moreover, a substantial scale up ( $>100 \mathrm{~g}$ ) experiment demonstrated simple applicability.

Financal support was provided by ETH Zurich and the Swiss Science Foundation (No. 200021-150179).

\section{Notes and references}

1 (a) E. Nakamura and S. Mori, Angew. Chem., Int. Ed., 2000, 39, 3750; (b) J. S. Johnson and D. A. Evans, Acc. Chem. Res., 2000, 33, 325; (c) D. A. Evans, D. M. Barnes, J. S. Johnson, R. Lectka, P. von Matt, S. J. Miller, J. A. Murry, R. D. Norcross, E. A. Shaughnessy and 
K. R. Campos, J. Am. Chem. Soc., 1999, 121, 7582; (d) H. J. Cristau, P. P. Cellier, J. F. Spindler and M. Taillefer, Chem. - Eur. J., 2004, 10, 5607; (e) A. Alexakis and C. Benhaim, Eur. J. Org. Chem., 2002, 3221; $(f)$ O. Daugulis, H.-Q. Do and D. Shabashov, Acc. Chem. Res., 2009, 42, 1074; $(g)$ I. P. Beletskaya and A. V. Cheprakov, Coord. Chem. Rev., 2004, 248, 2337.

2 P. E. Fanta, Chem. Rev., 1946, 38, 139.

3 (a) D. M. T. Chan, K. L. Monaco, R. P. Wang and M. P. Winters, Tetrahedron Lett., 1998, 39, 2933; (b) D. A. Evans, J. L. Katz and T. R. West, Tetrahedron Lett., 1998, 39, 2937; (c) P. E. Fanta, Synthesis, 1974, 9; (d) H. H. Hodgson, Chem. Rev., 1947, 40, 251; (e) P. Y. S. Lam, C. G. Clark, S. Saubern, J. Adams, M. P. Winters, D. M. T. Chan and A. Combs, Tetrahedron Lett., 1998, 39, 2941.

4 (a) H. C. Kolb, M. G. Finn and K. B. Sharpless, Angew. Chem., Int. Ed., 2001, 40, 2004; (b) C. W. Tornøe, C. Christensen and M. Meldal, J. Org. Chem., 2002, 67, 3057.

5 (a) K. C. Nicolaou, P. G. Bulger and D. Sarlah, Angew. Chem., Int. Ed., 2005, 44, 4442; (b) K. M. Bratlie, H. Lee, K. Komvopoulos, P. Yang and G. A. Somorjai, Nano Lett., 2007, 7, 3097; (c) G. C. Bond and D. T. Thompson, Catal. Rev., 1999, 41, 319.

6 (a) L. R. Madivada, R. R. Anumala, G. Gilla, S. Alla, K. Charagondla, M. Kagga, A. Bhattacharya and R. Bandichhor, Org. Process Res. Dev., 2009, 13, 1190; (b) C. A. Martinez, S. Hu, Y. Dumond, J. Tao, P. Kelleher and L. Tully, Org. Process Res. Dev., 2008, 12, 392; (c) S. D. Walker, C. J. Borths, E. DiVirgilio, L. Huang, P. Liu, H. Morrison, K. Sugi, M. Tanaka, J. C. S. Woo and M. M. Faul, Org. Process Res.
Dev., 2011, 15, 570; (d) E. Knoevenagel, Ber. Dtsch. Chem. Ges., 1898, 31, 2596.

7 L. F. Tietze and U. Beifuss, in Comprehensive Organic Synthesis, ed. B. M. T. Fleming, Pergamon, Oxford, 1991, pp. 341-394.

8 (a) A. Corma, V. Fornes, R. M. Martín-Aranda, H. Garcia and J. Primo, Appl. Catal., 1990, 59, 237; (b) A. Corma and R. M. Martín-Aranda, J. Catal., 1991, 130, 130; (c) B. C. Ranu and R. Jana, Eur. J. Org. Chem., 2006, 3767; (d) C. Su, Z.-C. Chen and Q.-G. Zheng, Synthesis, 2003, 0555; (e) E. M. Schneider, R. A. Raso, C. J. Hofer, M. Zeltner, R. D. Stettler, S. C. Hess, R. N. Grass and W. J. Stark, J. Org. Chem., 2014, 79, 10908; $(f)$ N. Mase and T. Horibe, Org. Lett., 2013, 15, 1854; $(g)$ Y. A. Sonawane, S. B. Phadtare, B. N. Borse, A. R. Jagtap and G. S. Shankarling, Org. Lett., 2010, $12,1456$.

9 R. N. Grass, E. K. Athanassiou and W. J. Stark, Angew. Chem., Int. Ed., 2007, 46, 4909.

10 F. M. Koehler, N. A. Luechinger, D. Ziegler, E. K. Athanassiou, R. N. Grass, A. Rossi, C. Hierold, A. Stemmer and W. J. Stark, Angew. Chem., Int. Ed., 2009, 48, 224.

11 (a) V. S. R. Rajasekhar Pullabhotla, A. Rahman and S. B. Jonnalagadda, Catal. Commun., 2009, 10, 365; (b) S. Komiya, T. Sone, Y. Usui, M. Hirano and A. Fukuoka, Gold Bull., 1996, 29, 131.

12 (a) N. Kränzlin, S. Ellenbroek, D. Durán-Martín and M. Niederberger, Angew. Chem., Int. Ed., 2012, 51, 4743; (b) N. Kränzlin and M. Niederberger, Adv. Mater., 2013, 25, 5599. 